\title{
Validation of national empirical pavement design approaches for cold recycled asphalt bases
}

\author{
M. Winter \& K. Mollenhauer \\ Universität Kasse, Germany
}

A. Graziani \& C. Mignini

Università Politecnica delle Marche, Italy

H. Bjurström \& B. Kalman

Statens väg- \& transportforskningsinstitut (VTI), Sweden

P. Hornych \& V. Gaudefroy

Université Gustave Eiffel, France

D. Lo Presti

Nottingham Transportation Engineering Centre (NTEC), UK

Università degli Studi di Palermo, Italy

G. Giancontieri

Università degli Studi di Palermo, Italy

\begin{abstract}
The applied pavement design procedures differ from country to country within Europe. Especially the use of cold recycling materials which is handled similar to hotmix asphalt (HMA) in the most available guidelines isn't sufficient researched. To verify developed procedures, practical trial sections are indispensable. Within this study cold recycled asphalt base layers $(\mathrm{CRAB})$ were assessed according to the German procedure for monitoring and evaluation of road surface conditions. It can be concluded, that the general applied empirical design approach, in which the CRAB layer thickness is increased by $50 \%$ compared to a HMA base will result in a feasible pavement structure. In general, the redesigning of the sections according to various national empirical pavement design approaches partly results in high differences for same layer types.
\end{abstract}

Keywords: Validation, Pavement Design, Cold Recycling, Reclaimed Asphalt

\section{INTRODUCTION}

Because of the European political goals regarding $\mathrm{CO}_{2}$-reduction gain more and more importance, each industry sector has to look for possibilities to slow down the greenhouse effect. Due to the resulting restrictions as well as the increasing maintenance work within the road network alternative construction methods are required. A solution to handle this circumstances could be the usage of cold recycled materials (CRM).

In comparison to hot mix asphalt (HMA) the recycling of reclaimed asphalt (RA) is more simple for cold recycling (CR). The procedure provides recycling rates of usually $\geq 75 \%$ 
(Mollenhauer \& Simnofske, 2016) and is applied at ambient temperature. This results in a reduction of around $10 \%$ for greenhouse gas emissions associated with a complete road structure (Giani et al., 2015).

Despite if there is practical experience with cold recycled materials and additionally wellresearched mechanical properties of CRM in laboratory-based projects, the pavement design procedure often leads to higher structural thickness compared to HMA. This can be justified because of the missing fatigue failure criteria for those materials. Therefore, the pavement design procedures in practice are different and may result in the same thickness estimations compared to hot bituminous materials (e.g. in Switzerland, (VSS Schweiz, 2011)) up to thickness-increase factors of e. g. $50 \%$ (Bocci et al., 2010) compared to standard HMA. Especially the time-dependent change of material strength during curing, which results in increasing bearing capacity of Cold Recycled Asphalt Bases (CRAB) structures over months or even years (Godenzoni et al., 2018), is one reason for this.

These thickness differences result in varying costs for the environmental-friendly technology and therefore in extremely different application rates within the various European countries (EAPA, 2018). This contribution analyses the various pavement structures with CRAB and tries to validate the designs regarding achieved pavements performance.

\section{METHODOLOGY}

As there are several road sections in Europe which contain cold recycled or cold bounded material as base layer, an assessment of the structural performance for existing pavements in four selected countries is conducted. To validate the national empirical pavement design procedures from Germany, Italy and UK, the observations regarding structural design, loading parameters and pavement conditions for the existing CRAB pavement sections are assessed. The validation is split in 3 phases.

Firstly, the individually applied traffic load parameter is calculated for all pavement structures. These are the number of equivalent standard axle loads, which are based on the composition and volume of heavy traffic as well as the aimed service lifetime.

In a second step, each empirical design procedure is applied for each of the CRAB pavement sections. This will allow the direct comparison of the three design procedures.

At last, the structural performance is estimated by taking the actual service lifetime into account. By these means, a theoretical residual service life parameter is estimated for each section which can be compared with the actually observed pavement condition.

\section{PERFORMANCE AND CONDITION PARAMETER OF EXISTING STRUCTURES}

\subsection{Studied sections}

From each selected country (GE, ITA, SWE, UK) 2-4 road sections were selected, where cold recycling material has been included in the base layer. In Figure 1 the pavement design of all studied sections are shown. Structural designs for the road sections are presented from the surface layer down to the bitumen or cement bound bottom layer. This is the CRAB layer for all road sections, except for two of the UK sections and one Italian section where cement bound foundation is below the CRAB layer. The structures are demonstrating a large variation in traffic loading and climatic conditions (location) as well as design approach. (Bjurström et al., 2020).

\subsection{Structural performance}

The internationally applied procedures for monitoring differ considerably. For allowing a comparison of the structural design success, a common procedure for the assessment of the pavement condition is required. Therefore, the German procedure for monitoring and 


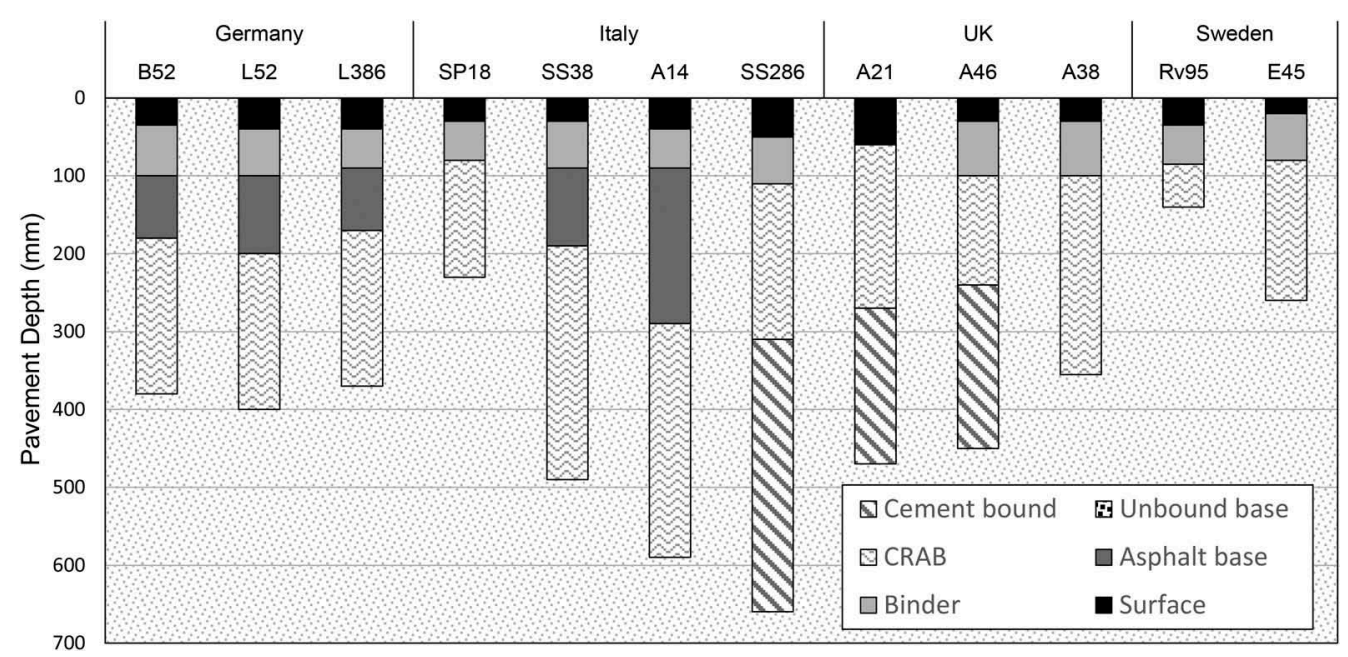

Figure 1. Layer thicknesses for the studied road sections illustrated from the surface down to the deepest bound layer (Bjurström et al., 2020).

evaluation of road surface conditions of federal highways (FGSV, 2001) was applied to all pavements. The measured surface condition is transferred to condition quality categories as followed:

$<1,5$ : very good/new road structure

$1,5-2,49$ : good

$2,5-3,49$ : satisfactory

3,5 - 4,49: sufficient, but maintenance methods should be prepared $\geq 4,5$ : defective, maintenance is required shortly

The transfer functions from the measured condition value to the quality categories is calculated linearly for the transfer parameters according to Table 1. The permanent deformation in terms of rut depth measurement in millimeters was available for the pavements in Germany, Sweden and UK. The proportion of cracking in the road surface was available for pavements from Germany only. In order to include this assessment for the other pavements, the proportion of cracked surfaces was estimated by analyzing photographs taken from the road pavement. Here, Google Street View photos (https://www.google.com/maps) were partially used, which allowed the rough assessment of cracks. As the sections were of various lengths, and the categories varied within each section, the arithmetic mean category value was calculated as well as the standard deviation. From these, the $95 \%$ quantile category value was calculated in order to assess the variability of the pavement condition.

Table 1. Surface condition transfer parameters according to (FGSV, 2001).

\begin{tabular}{lllll}
\hline Surface condition quality category & 1,5 & 2,5 & 3,5 & 4,5 \\
Rut depth [mm] & 4 & 7 & 10 & 20 \\
Proportion of cracked surface [\%] & 1 & 7 & 15 & 25 \\
\hline
\end{tabular}

The results of the surface condition assessment are listed in Table 2. For each section the year of the implementation of the CRA pavement is given (year of rehabilitation). Further, the newest result for the surface monitoring assessment is given as well as the average daily traffic of heavy vehicles. For the rutting depth and the cracking, the mean quality values are given (in bold) as well as the $95 \%$ quantile (in italic). 
In general, the mean surface conditions of most of the assessed sections is very good or good. The Italian section SP18 is the only one which results in satisfactory condition with a mean quality higher than 2,5 .

Table 2. Pavement condition according to the German standard (FGSV, 2001) of each section since rehabilitation.

\begin{tabular}{|c|c|c|c|c|c|c|}
\hline \multirow[t]{2}{*}{ Country } & \multirow[t]{2}{*}{ Section } & \multirow[t]{2}{*}{$\begin{array}{l}\text { Year of } \\
\text { Rehabilitation }\end{array}$} & \multirow[t]{2}{*}{$\begin{array}{l}\text { Last year of } \\
\text { Measurement }\end{array}$} & \multirow{2}{*}{$\begin{array}{l}\text { Daily } \\
\text { heavy } \\
\text { traffic }\end{array}$} & \multicolumn{2}{|c|}{ quality value* } \\
\hline & & & & & rutting & cracking \\
\hline \multirow{2}{*}{ GER } & \multirow{2}{*}{ B52 } & \multirow{2}{*}{2009} & \multirow{2}{*}{2015} & \multirow{2}{*}{3900} & 1,88 & 1,04 \\
\hline & & & & & 2,18 & 1,20 \\
\hline \multirow{2}{*}{ GER } & \multirow{2}{*}{ L52 } & \multirow{2}{*}{2011} & \multirow{2}{*}{2017} & \multirow{2}{*}{60} & 1,28 & 1,00 \\
\hline & & & & & 2,00 & 1,00 \\
\hline GER & \multirow{2}{*}{ L386 } & \multirow{2}{*}{2007} & \multirow{2}{*}{2017} & \multirow{2}{*}{365} & 1,50 & 1,36 \\
\hline \multirow[b]{2}{*}{ SWE } & & & & & 1,79 & 3,45 \\
\hline & Rv95 & \multirow{2}{*}{2014} & 2019 & \multirow{2}{*}{380} & 2,10 & 1,35 \\
\hline \multirow[b]{2}{*}{ SWE } & \multirow[b]{2}{*}{$\mathrm{E} 45$} & & \multirow[b]{2}{*}{2019} & & 174 & 154 \\
\hline & & 2012 & & 333 & $\begin{array}{l}1,14 \\
181\end{array}$ & 279 \\
\hline \multirow{2}{*}{ ITA } & \multirow{2}{*}{$\mathrm{SS} 38$} & \multirow{2}{*}{2007} & \multirow{2}{*}{2019} & 1850 & & 1,00 \\
\hline & & & & 1850 & & 1,00 \\
\hline ITA & SS268 & 2016 & 2017 & 2115 & & 1,00 \\
\hline & & & & & & 1,00 \\
\hline ITA & SP18 & 2008 & 2019 & 250 & & $\begin{array}{l}2,74 \\
4,50\end{array}$ \\
\hline ITA & $\Delta 14$ & 2007 & 2010 & 11000 & & 1,18 \\
\hline $11 \mathrm{~A}$ & A14 & 2007 & 2019 & 11000 & & 1,73 \\
\hline UK & A46 & 2006 & 2018 & 3664 & 1,64 & 1,36 \\
\hline & & & & & 1,84 & 1,82 \\
\hline UK & A21 & 2002 & 2018 & 11700 & 1,56 & 1,00 \\
\hline
\end{tabular}

* status value written in bold and a 95-\% quantile written in italic

However, when considering the variation of the surface condition, additional sections can be identified with problematic performance on a part of the total length. This is indicated by higher 95\%-quantile values on sections L386 (GER), Rv95 and E45 (SWE).

\section{VALIDATION OF NATIONAL EMPIRICAL DESIGN APPROACHES}

\subsection{Comparative evaluation of the traffic loads}

A common design parameter is the traffic load. In all design procedures, the average daily traffic of heavy vehicles and the aimed service lifetime is used for calculating the number of equivalent standard axle loads (ESAL). Here, the three design procedures apply different load values for the standard axle load (ITA, UK: 8,2 t; GER, SWE: $10 \mathrm{t}$ ). Additionally, different aimed service lifetimes are considered: GER, ITA, SWE: 30 a; UK: 40 a.

In order to base the different pavement design on the same traffic load estimations, the individual number of equivalent standard axles of the considered country, where the structure is located is used as an input value. The other two traffic volume parameters are then calculated, by application of the "power 4-law". By these means, the different approaches for traffic 
Table 3. Traffic load parameters of CRAB validation structures (Millions of equivalent standard axle loads (ESAL: GER, SWE, ITA; msa: UK)).

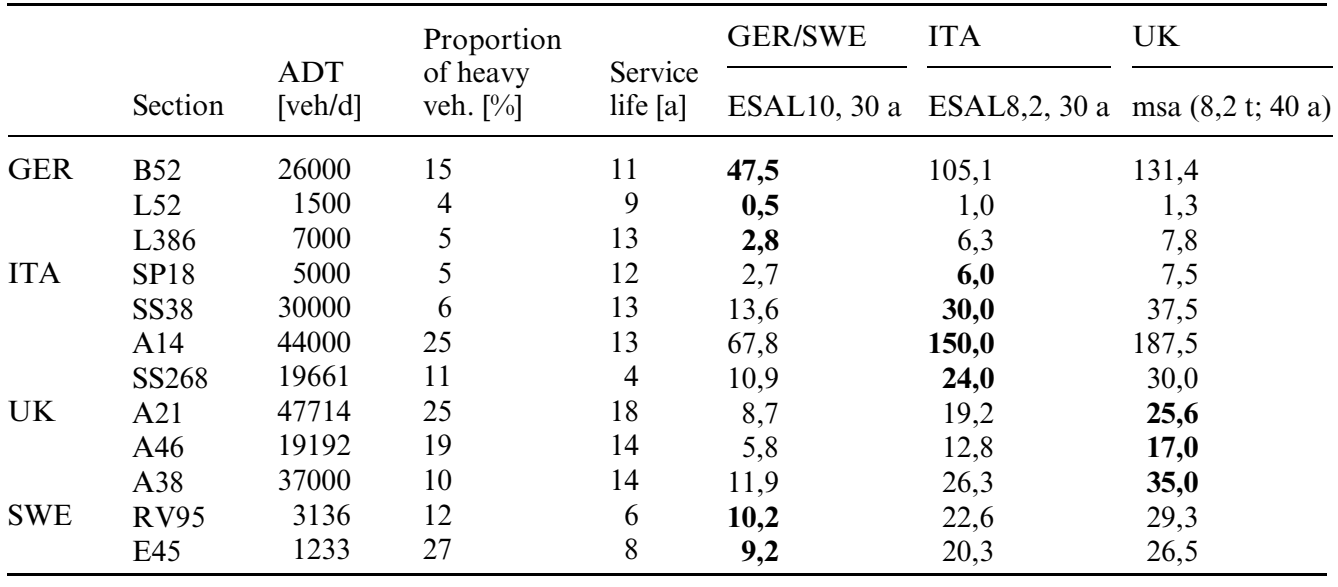

assessment and estimation of the equivalent load parameters are biased. The resulting numbers of ESAL are summarized in Table 3. The basic traffic parameter is printed in bold, from which the other two parameters were calculated.

\subsection{Re-design of the existing pavements}

In this section, the existing pavements were re-designed according to the national standards of Germany (FGSV, 2005, 2012), UK (Merrill et al., 2004) and Italy (Autonome Provinz Bozen Südtirol, 2016; Consiglio Nazionale Delle Ricerche, 1995). For the design procedures of Germany and Italy, the deformation modulus $\mathrm{E}_{\mathrm{V} 2}$ is the parameter for considering subbase bearing capacity. For the UK, the design depends on the foundation class. For deformation moduli between two foundation classes, the layer thickness according to UK design was linearly interpolated. The design procedures define different bearing capacity classes. For the catalogue systems (GER, ITA), this results in different modulus classes applied.

Table 4 shows an example for the re-design of the Italian pavement of SS268. The actual pavement structure has a total thickness of bound layers of $31 \mathrm{~cm}$. The re-design results in higher thickness values: GER: $36 \mathrm{~cm}$, UK: $35,5 \mathrm{~cm}$ and IT: $30 \mathrm{~cm}$ (with additional stabilized subbase). Obviously, the actual thickness of the pavement is lower than the designed values according to German and UK pavement design.

The surface condition values (mean/95\%-quantile) for this section are 2,74/4,5 (compare Table 2). The observed cracking in the pavement correlates to the undersized design.

The resulting total thickness values of the bituminous layers for all studied road sections are summarized in Table 5. For the re-designed thickness results, the thickness-deviation of the actual pavements are given and highlighted by different font types:

- Bold: actual thickness is higher compared to re-designed thickness

- Standard: actual thickness is the same $( \pm 2 \mathrm{~cm})$ as the re-designed thickness

- Italic: actual thickness is lower than the re-designed thickness.

The three assessed empirical design procedures identify over- and under-designed pavement structures in the assessed roads similarly. Despite of differences in re-design thickness of up to $7 \mathrm{~cm}$ (section E45), the German and UK design procedure are capable to identify the same sections as under- (red) or overdesigned. However, the pavements designed according to the UK specifications are generally thinner compared to the German design thickness, with B52 as an exception. 
Table 4. Results for redesigned pavement of the Italian section S268.

\begin{tabular}{lrrrr}
\hline \multirow{2}{*}{ SS268 } & Current state & \multicolumn{2}{l}{ Redesigned pavement } \\
\cline { 3 - 5 } & & ESAL10 & msa8.2 & ESAL8.2 \\
\hline ESAL/msa & 0,8 & $10,9^{1)}$ & 30,0 & 24,0 \\
deformation modulus subbase & $160^{2)}$ & 150 & 160 & 160 \\
surface & 5 & 4 & 4 & 3 \\
binder & 6 & 0 & 6 & 7 \\
base & 0 & 8 & 25,5 & 0 \\
CRAB & 20 & & 35,5 & 30 \\
stabilized base layer & 35 & 36 & 30 \\
Total asphalt thickness & 31 & &
\end{tabular}

1) Extrapolation within the design procedure; ${ }^{2)}$ Estimation because of missing data

For the Italian re-design results, the thickness of all structures is lower compared to English or German designs. However, these CRAB structures are based on top of a cement stabilized layer, which gives higher bearing capacity. Generally, the same differences between the actual pavement structure thickness and the designed ones are identified also with the Italian method with the B52 as an exception. In three cases (SP18, SS268 and A46) the difference between pavement thickness and re-designed thickness is lower than $\pm 2 \mathrm{~cm}$.

Four of the pavements (L52, L386, SS38 and A14) seem to be over-designed according to all design procedures applied. Three of these structures are identified by a very low crack condition value and nearly show no crack damage at all (see Table 2). The exception for this conclusion is section L286, where cracking could be observed in some specific spots and which originally showed transversal cracking shortly after construction and which was maintained.

Of the six structures that are identified as under-designed: SP18, SS286, A21, A46, Rv95 and E45, three actually show some (Rv95, E45) or considerable (SP18) crack damages.

\subsection{Calculation of structural condition parameter}

As can be observed from Table 5, there is only a low correlation between the thickness differences between design thickness and actual thickness and the observed cracking in the pavements. One reason is, that the design life is considerably higher for all of the assessed structures than the actual service lifetime (compare Table 3). In order to consider the actual received traffic loading on the assessed pavements, a theoretical structural condition parameter is calculated according to a German guideline document (FGSV, 2019).

Therefore, the required thickness $\left(\mathrm{DI}_{\text {erf. }}\right.$ ) of the bound layers are calculated by considering the traffic load class and the bearing capacity of the unbound subbase. This thickness is compared to the "active" thickness $\left(\mathrm{DI}_{\mathrm{vorh}}\right)$ of the assessed pavement structure, where the actual thicknesses of the structural layers are reduced according to the age of the layer.

The active thickness of the existing pavement $\mathrm{DI}_{\mathrm{vorh}}$ is given in the following equation:

$$
D I_{\text {vorh. }}=\sum_{i}\left(D_{i} * A q_{i t}\right)
$$

where:

$D_{i}=$ Thickness of the bound layer $\mathrm{i}[\mathrm{cm}]$

$\mathrm{Aq}_{\mathrm{i} t}=$ age-related factor of thickness equivalation of the layer $\mathrm{i}$ (see Table 6)

$\mathrm{Aq}_{\mathrm{it}}=\mathrm{MIN}\left(\mathrm{Aq}_{\mathrm{i} \max } ; \mathrm{MAX}\left(\mathrm{Aq}_{\mathrm{i} \text { min }} ;\right.\right.$ Equation according to Table 6)) 
Table 5. Real and design thickness according to different empirical design approaches.

\begin{tabular}{|c|c|c|c|c|c|}
\hline \multirow{2}{*}{ Section } & \multirow{2}{*}{$\begin{array}{l}\text { Actual thickness } \\
{[\mathrm{cm}]}\end{array}$} & \multicolumn{3}{|c|}{$\begin{array}{l}\text { Thickness according to national standards* } \\
{[\mathrm{cm}]}\end{array}$} & \multirow{2}{*}{$\begin{array}{l}\text { Crack condition value: } \\
\text { (mean } 95 \% \text {-quantile) }\end{array}$} \\
\hline & & GER & UK & ITA & \\
\hline \multirow[t]{2}{*}{ B52 } & 38 & 38 & 42 & 35 & 1,04 \\
\hline & $\Delta[\mathrm{cm}]$ & 0 & 4 & -3 & 1,2 \\
\hline \multirow[t]{2}{*}{ L52 } & 40 & 28 & 28,5 & 21 & 1,0 \\
\hline & $\Delta[\mathrm{cm}]$ & -12 & -12 & -19 & 1,0 \\
\hline \multirow[t]{2}{*}{ L386 } & 37 & 32 & 27,5 & 21 & 1,36 \\
\hline & $\Delta[\mathrm{cm}]$ & -5 & -10 & -16 & 3,45 \\
\hline \multirow[t]{2}{*}{ SP18 } & 23 & 32 & 37 & 21 & 2,74 \\
\hline & $\Delta[\mathrm{cm}]$ & 9 & 14 & -2 & 4,5 \\
\hline \multirow[t]{2}{*}{ SS38 } & 49 & 40 & 34,5 & 36 & 1,0 \\
\hline & $\Delta[\mathrm{cm}]$ & -9 & -15 & -13 & 1,0 \\
\hline \multirow{2}{*}{ A14 } & 59 & 38 & 44 & 35 & 1,18 \\
\hline & $\Delta[\mathrm{cm}]$ & -21 & -15 & -24 & 1,73 \\
\hline \multirow[t]{2}{*}{$\mathrm{SS} 268$} & 31 & 36 & 35,5 & 30 & 1,0 \\
\hline & $\Delta[\mathrm{cm}]$ & 5 & 5 & -1 & 1,0 \\
\hline \multirow[t]{2}{*}{ A21 } & 27 & 34 & 32 & 31 & 1,0 \\
\hline & $\Delta[\mathrm{cm}]$ & 7 & 5 & 4 & 1,0 \\
\hline \multirow[t]{2}{*}{ A46 } & 24 & 34 & 30 & 25 & 1,36 \\
\hline & $\Delta[\mathrm{cm}]$ & 10 & 6 & 1 & 1,82 \\
\hline \multirow[t]{2}{*}{ A38 } & 35,5 & 36 & 34 & 36 & - \\
\hline & $\Delta[\mathrm{cm}]$ & 0,5 & $-1,5$ & 0,5 & - \\
\hline \multirow[t]{2}{*}{ Rv95 } & 14 & 40 & 33,5 & 31 & 1,35 \\
\hline & $\Delta[\mathrm{cm}]$ & 26 & 20 & 17 & 2,75 \\
\hline \multirow[t]{2}{*}{ E45 } & 26 & 40 & 33 & 31 & 1,54 \\
\hline & $\Delta[\mathrm{cm}]$ & 14 & 7 & 5 & 2,79 \\
\hline
\end{tabular}

* standard: same thickness $( \pm 2 \mathrm{~cm}$ ), bold: actual thickness is higher, italic: actual thickness is lower

Table 6. Age-related factor of thickness equivalation for different types of layers.

\begin{tabular}{ll}
\hline Layer type & Age-related factor of thickness equivalency $\mathrm{Aq}_{\mathrm{i} t}$ with $\mathrm{t}=$ age of layer $[\mathrm{a}]$ \\
\hline Surface asphalt & $0,35<1,0392-\mathrm{t}^{*} 0,0392<1$ \\
Mastic asphalt & $0,4<1,0192-\mathrm{t}^{*} 0,0192<1$ \\
Asphalt Binder & $0,4<1,0400-\mathrm{t} * 0,0200<1$ \\
Asphalt Base & $0,5<1,0200-\mathrm{t}^{*} 0,0100<1$ \\
Hydraulic bound & $0,33<0,5540-\mathrm{t} * 0,0070<0,54$ \\
\hline
\end{tabular}

The equations for calculation $D I_{\text {erf }}$ are based on the German design catalogue structures and have input parameters linked to the number of equivalent axle loads (10 t, $30 \mathrm{a})$ and the subbase bearing capacity in terms of deformation modulus $\mathrm{E}_{\mathrm{V} 2}$. The resulting loading class (Bk) refer to the upper limit of million 10-t-ESAL for each design catalogue column and regression equation.

The ratio of these values (called "thickness comparison number DVZ") is used as an indicator for the structural thickness reserve, which is already reduced by traffic loading (eq. 1).

$$
D V Z=\frac{D I_{\text {vorh }}}{D I_{\text {erf }}}
$$

This number is the basis for assessment of a structural condition indicator, where a DVZ of 0,9 (thickness reserve is reduced by $10 \%$ ) is considered as "very good" and a DVZ of $50 \%$ 
(structural thickness is reduced to half of its initial value) is considered as defective. By this estimation, a structural condition parameter SW is obtained, which can be directly compared with surface condition parameters. The determination of the parameter SW is based on a standardization function, which takes into account the thickness comparison number DVZ.

This comparison is shown in Figure 2, where the observed surface parameter (maximum of the $95 \%$-quantile of cracking or rutting) is plotted against the structural condition parameter $\mathrm{SW}_{\mathrm{B}}$. Considering the different design approaches, there is a relatively good correlation between these two parameters, representing all assessed CRAB pavements. This further indicates, that the observed performance is linked to the structural design of these pavements and can be used as a parameter to evaluate the success of an applied pavement design.

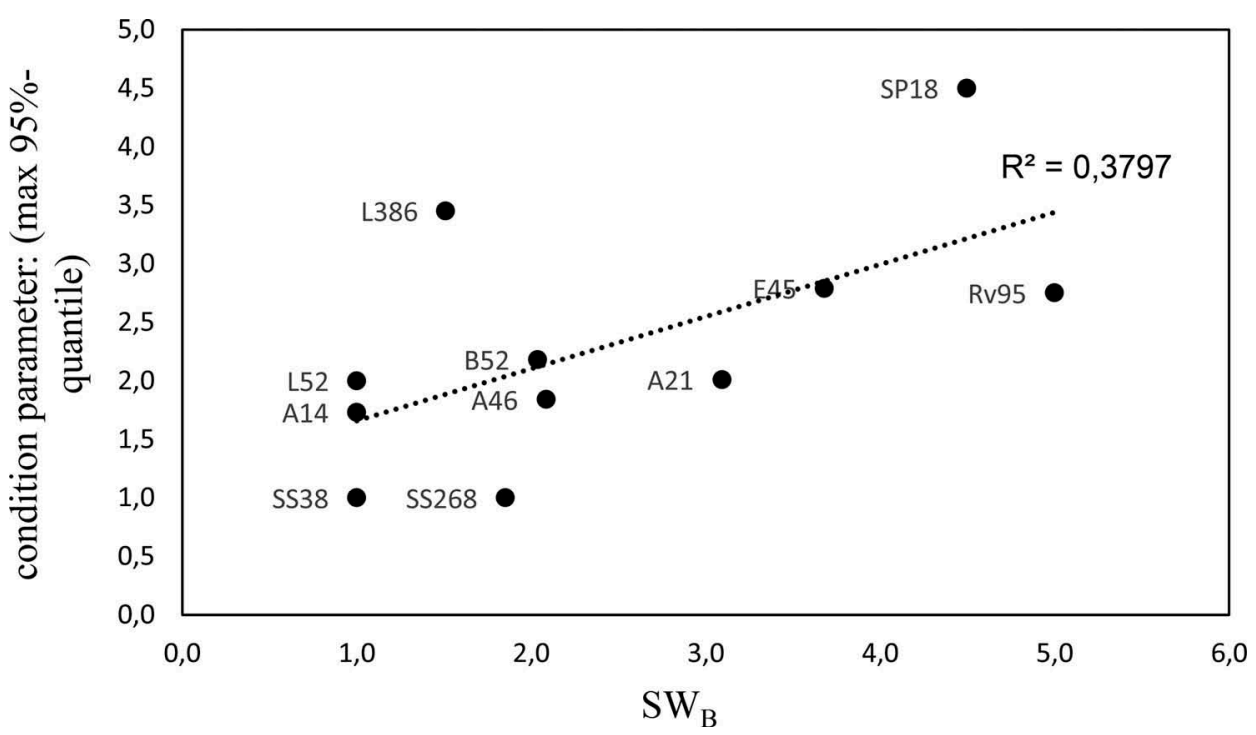

Figure 2. Comparison of structural condition parameter $\mathrm{SW}_{\mathrm{B}}$ with surface cracking conditions for the assessed CRAB pavements.

\section{CONCLUSIONS}

The structural performance of existing CRAB pavement structures was assessed in detail. Regarding the surface condition performance, eight of these 12 structures showed none or only very little rutting or cracking, two showed some cracking which can be considered as moderate and only two sections showed defective surface cracking on some parts of the pavement area. This observed surface performance could be correlated against the difference between actually applied structural thickness and the required thickness (according to German, Italian or UK design) only roughly. However, when the actual service life is considered within this comparison, a close correlation between the surface condition and the theoretical design life could be identified. In this way it could be observed, that the structures of the Swedish pavements as well as an Italian pavement, have a shorter remaining expected service life. It must be emphasized, that a German procedure was applied for estimating the theoretical service life, which is based on German pavement design thickness results. 
However, the good surface conditions of most assessed sections clearly show, that the construction of durable pavements with CRAB is possible. For three of the four sections with only moderate or even defective condition, the thickness of the pavement structures could be identified as not sufficient for the traffic loading conditions. Therefore, it can be concluded, that the generally applied empirical design approach, in which the CRAB layer thickness is increased by $50 \%$ compared to a HMA base will result in a feasible pavement structure.

For the assessment of cracking phenomena in pavements with CRAB layers, additional research is required in order to identify the origin of the cracks. It has to be identified if the crack result from traditional bottom-up cracks in the CRAB layer or rather in the asphalt surfacing as a result of low thickness and low bearing capacity of the CRAB layer. This may be related to the $\mathrm{CRAB}$ composition (e.g. cement content) but could not be analyzed within this contribution.

\section{ACKNOWLEDGEMENT}

The work reported here is part of the project "CRABforOERE - Cold recycled asphalt bases for optimized energy \& resource efficient pavements" funded by the CEDR Transnational Road Research Programme Call 2017: Materials funded by Austria, Belgium-Flanders, Denmark, Germany, Netherlands, Norway, Slovenia, Sweden and the United Kingdom

\section{REFERENCES}

Autonome Provinz Bozen - Südtirol. (2016). Verzeichnis der Bezugsbauweisen zur Dimensionierung von Asphaltstrassen.

Bjurström, H., Kalman, B., Mollenhauer, K., Winter, M., Graziani, A., Mignini, C., Lo Prest, D., Giancontieri, G., \& Gaudefroy, V. (2020). Experiences from cold recycled materials used in asphalt bases: a comparison between five European countries.

Bocci, M [M.], Canestrari, F., Grilli, A., Pasquini, E., \& Lioi, D. (2010). Recycled Techniques and Environmental Issues Relating to the Widening of an High Traffic Volume Italian Motorway. International Journal of Pavement Research and Technology(3), 171-177.

Consiglio Nazionale Delle Ricerche (1995). Catalogo delle pavimentazioni stradali. Bollettino Ufficiale CNR. Rom. Consiglio Nazionale Delle Ricerche.

EAPA. (2018). Asphalt in Figures. Belgium. European Asphalt Pavement Association.

FGSV (2001). FGSV-Arbeitspapier Nr.9/A 1.2 zur ZEB. (Arbeitspapier, 9). Köln. FGSV-Verlag.

FGSV. (2005). Merkblatt für Kaltrecycling in situ im Straßenbau - M KRC. FGSV-Verlag.

FGSV. (2012). Richtlinien für die Standardisierung des Oberbaus von Verkehrsflächen: RStO 12. FGSVVerlag.

FGSV (2019). Richtlinien zur Bewertung der strukturellen Substanz des Oberbaus von Verkehrsfächen in Asphaltbauweisen. (Richtlinie). Köln. FGSV-Verlag.

Giani, M. I., Dotelli, G., Brandini, N., \& Zampori, L. (2015). Comparative life cycle assessment of asphalt pavements using reclaimed asphalt, warm mix technology and cold in-place recycling. Resources, Conservation and Recycling, 104, 224-238.

Godenzoni, C., Graziani, A., Bocci, E., \& Bocci, M [Maurizio] (2018). The evolution of the mechanical behaviour of cold recycled mixtures stabilised with cement and bitumen: field and laboratory study. Road Materials and Pavement Design, 19(4), 856-877.

Merrill, D., Nunn, M., \& Carswell, I. (2004). A guide to the use and specification of cold recycled materials for the maintenance of road pavements: TRL Report TRL 611 (TRL 611). London. Department of Transport.

Mollenhauer, K., \& Simnofske, D. (2016). Tolerances for inhomogeneity of pavement structure for insitu cold recycling. In K. Suchý (Ed.), 6th Eurasphalt \& Eurobitume Congress: 2016 (1st ed.). CTU Prague.

VSS Schweiz (2011). Dimensionierung des Strassenaufbaus; Unterbau und Oberbau. (SN 640324). Zürich. Verband der Strassen- und Verkehrsfachleute 